\title{
Bilateral Mirror Image Dural Arteriovenous Malformations Presenting with Aggressive Neurological Deterioration
}

Archie Defillo ${ }^{1}$, Andrea M. Zelensky ${ }^{2}$, Jodi Lowary ${ }^{3}$, Leslie A. Nussbaum ${ }^{4}$, Eric S. Nussbaum 5

1. Centracare Hospital 2. St. Joseph's Hospital, St. Paul, MN 3. Neurovascular and Skull Base Surgery, John Nasseff Neuroscience Institute, MN 4. Midwest Brain Tumor Center, John Nasseff Neuroscience Institute 5. John Nasseff Neuroscience Institute, MN Neurovascular \& Skull Base Surgery, National Brain Aneurysm Center at the John Nasseff Neuroscience Institute, MN Neurovascular \& Skull Base Surgery

$\square$ Corresponding author: Eric S. Nussbaum, lnussbaum@comcast.net

Disclosures can be found in Additional Information at the end of the article

\section{Abstract}

Background: Multiple dural arteriovenous malformations occur rarely in the same individual. We describe a patient with bilateral, mirror image, dural arteriovenous malformations (DAVMs). This unusual case raises interesting questions regarding the origin of DAVMs.

Case Description: We report the case of a 63-year-old hypertensive man who presented with the acute onset of confusion associated with a mixed expressive and receptive dysphasia. His medical history was significant for the recent institution of anticoagulation to manage atrial flutter. Digital subtraction angiography confirmed the presence of bilateral DAVMs. The vein of Labbe on both sides demonstrated only retrograde cortical venous filling from the malformations. Treatment included combined endovascular and microsurgical strategies.

Conclusion: We describe an unusual case of bilateral dural AVMs involving the transverse sigmoid junction. Both lesions were associated with retrograde cortical venous drainage, and the larger left-sided lesion presented with hemorrhage necessitating surgical intervention. The origin of these lesions remains poorly understood, and this case may add to our understanding of this entity.

Categories: Neurosurgery

Keywords: dural arteriovenous malformation, arteriovenous malformation, microsurgery

Received 02/26/2014 Review began 02/27/2014 Review ended 03/25/2014 Published 03/26/2014

\section{Copyright 2014}

Defillo et al. This is an open access article distributed under the terms of the Creative Commons Attribution License CC-BY 3.0., which permits unrestricted use, distribution, and reproduction in any medium, provided the original author and source are credited.

\section{Introduction}

Dural arteriovenous malformation/fistula accounts for 10 to $15 \%$ of all intracranial arteriovenous lesions $[1,2,3]$. It is estimated that fewer than $2 \%$ of patients harbor multiple lesions $[1,4,5]$. We describe a patient with bilateral, mirror image, dural arteriovenous malformations. Both lesions were associated with retrograde cortical venous drainage, and the larger left-sided lesion presented with hemorrhage necessitating surgical intervention. This unusual case raises interesting questions regarding the origin of DAVMs.

\section{Materials And Methods}

We retrospectively reviewed the hospital notes, outpatient records, and imaging studies of the 


\section{Cureus}

patient that forms the basis for this report. A literature review using Pubmed and Medline search engine databases was performed to evaluate cases of bilateral and/or mirror image vascular malformations of the brain.

\section{Results}

\section{Case report}

A 63-year-old hypertensive man presented with the acute onset of confusion associated with a mixed expressive and receptive dysphasia. His medical history was significant for the recent institution of anticoagulation to manage atrial flutter. On arrival to a rural emergency department, his NIHSS score was 2, and his initial MRI revealed a $3.5 \mathrm{~cm}$ mixed density left temporal intraparenchymal hemorrhage.

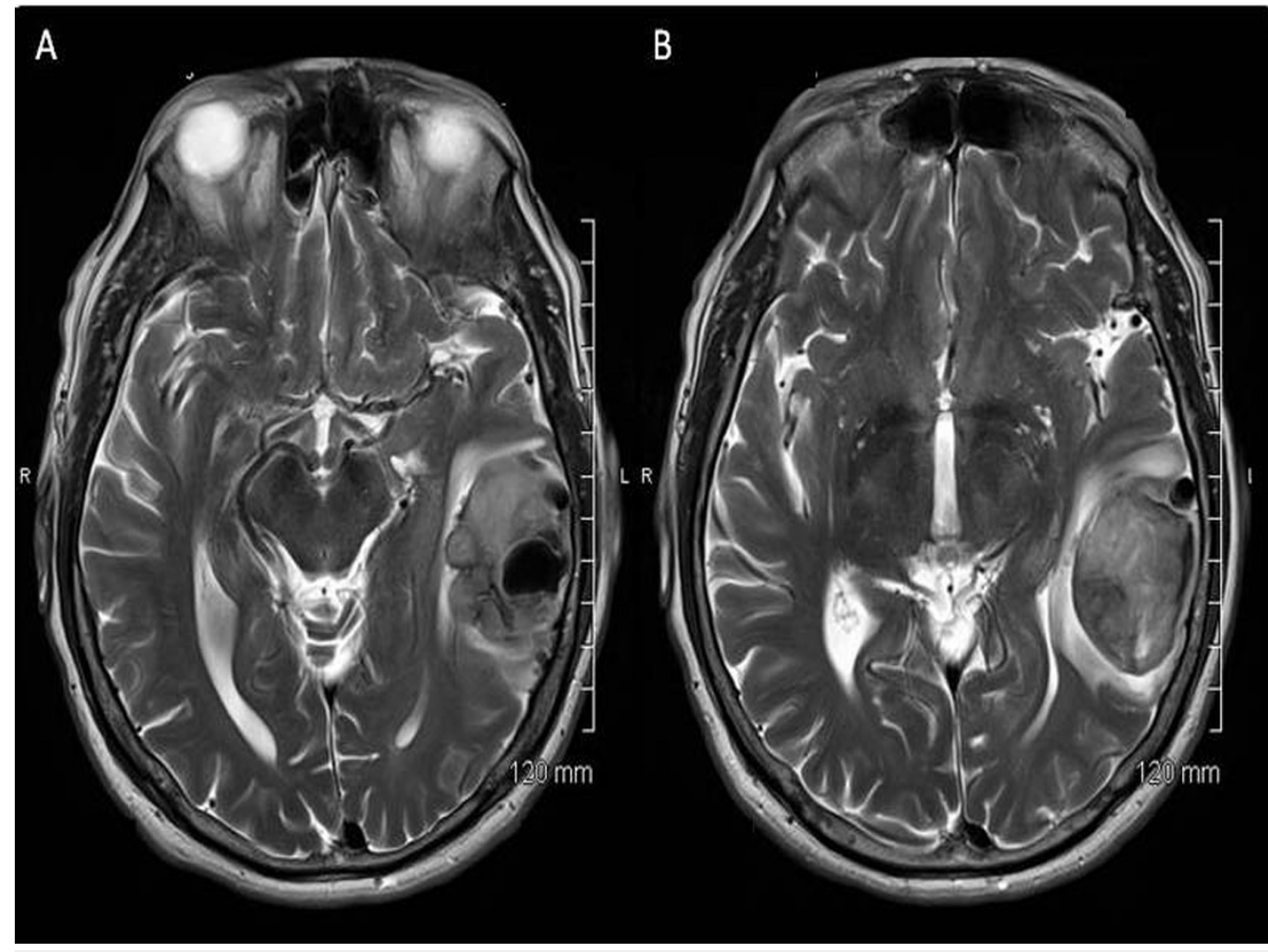

FIGURE 1: Fig. 1A\&B Axial MRI demonstrating an enlarging acute intraparenchymal hematoma involving the left temporal lobe associated with vasogenic edema.

There is partial effacement of the atrium and temporal portion of the lateral ventricle. Of note is the presence of a venous aneurysm associated with the hematoma.

His international normalized ratio (INR) was 2 at the time of presentation. He received two units of fresh frozen plasma, $5 \mathrm{mg}$ of vitamin $\mathrm{K}$, and was loaded with an anticonvulsant. Prior to transfer, his neurological condition worsened requiring intubation, mechanical ventilation, and aggressive blood pressure control. A repeat MRI demonstrated slight enlargement of the intracranial hematoma, expanding to $3.9 \mathrm{~cm}$. An osmotic diuretic was infused before transport. 


\section{Cureus}

On arrival to our center, he was sedated and fully paralyzed which precluded meaningful neurological examination. MRI/A re-demonstrated a now $5.8 \mathrm{~cm}$ hematoma in the posterior inferolateral left temporal lobe. Associated with this lesion were multiple dilated draining veins present over the surface of the brain, including a $1.8 \mathrm{~cm}$ venous aneurysm that projected into the hematoma. Additionally, there was a mirror image tangle of vessels in the posterior inferior right temporal lobe suggesting a small similar dural arteriovenous fistula.

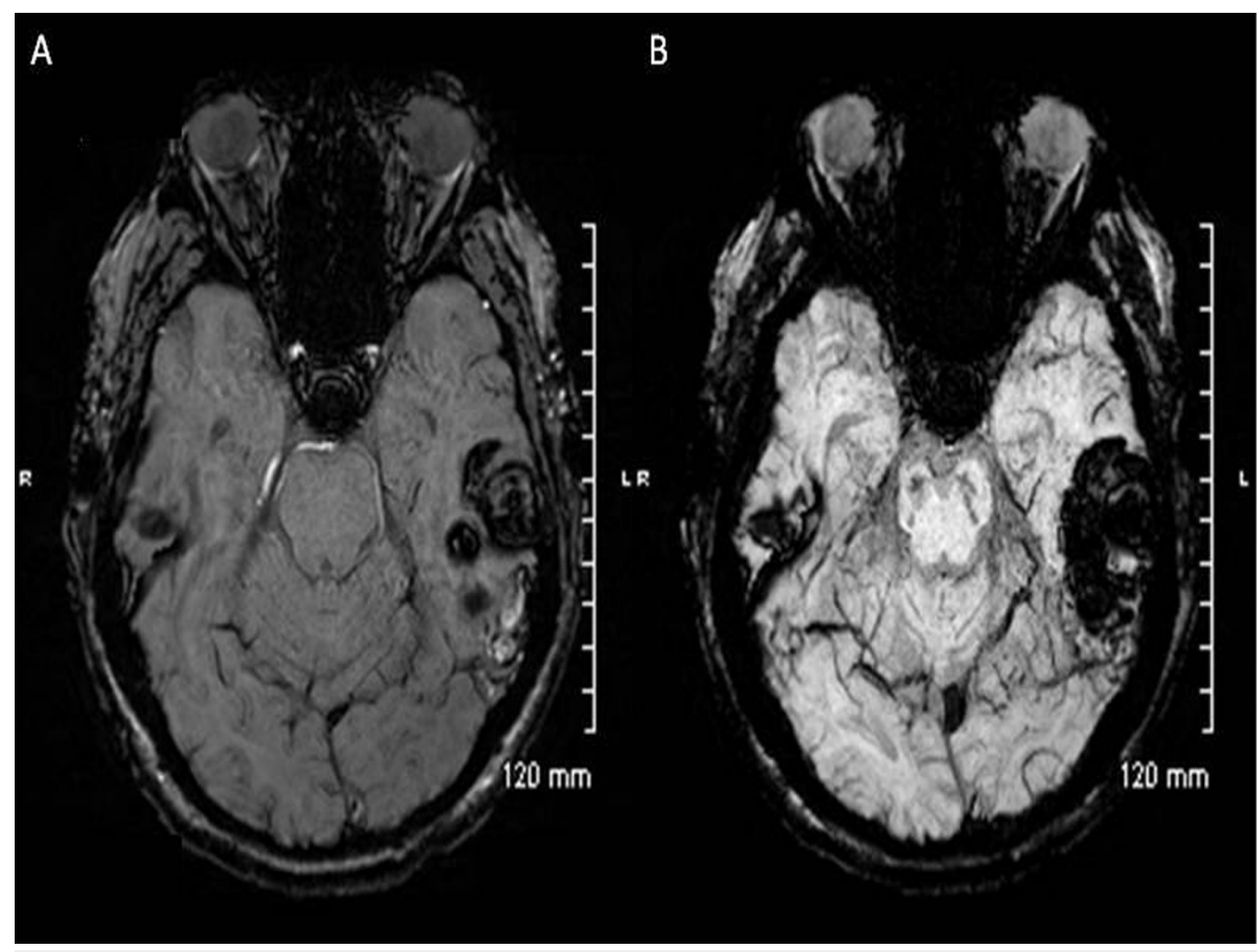

FIGURE 2: Fig. 2A\&B. MRA showing an additional mirror image tangle of vessels in the posterior inferior right temporal lobe suggesting a small similar dural AV fistula.

The digital subtraction angiogram confirmed the presence of bilateral DAVMs. The vein of Labbe on both sides demonstrated only retrograde cortical venous filling from the malformations.

The left-sided lesion's arterial supply consisted of a significantly hypertrophied middle meningeal branch which connected to the nidus near the junction of the left vein of Labbe with the transverse sinus. Additional arterial feeders included the marginal tentorial artery and transcalvarial occipital branches. The vein of Labbe filled briskly in retrograde fashion and drained anteriorly into the cavernous sinus and what appeared to be the vein of Trolard, which then drained into the superior sagittal sinus. There was a relatively large $10 \mathrm{~mm}$ venous aneurysm located at Labbe's mid-portion adjacent to the temporal hematoma and presumed to be the source of hemorrhage. 


\section{Cureus}

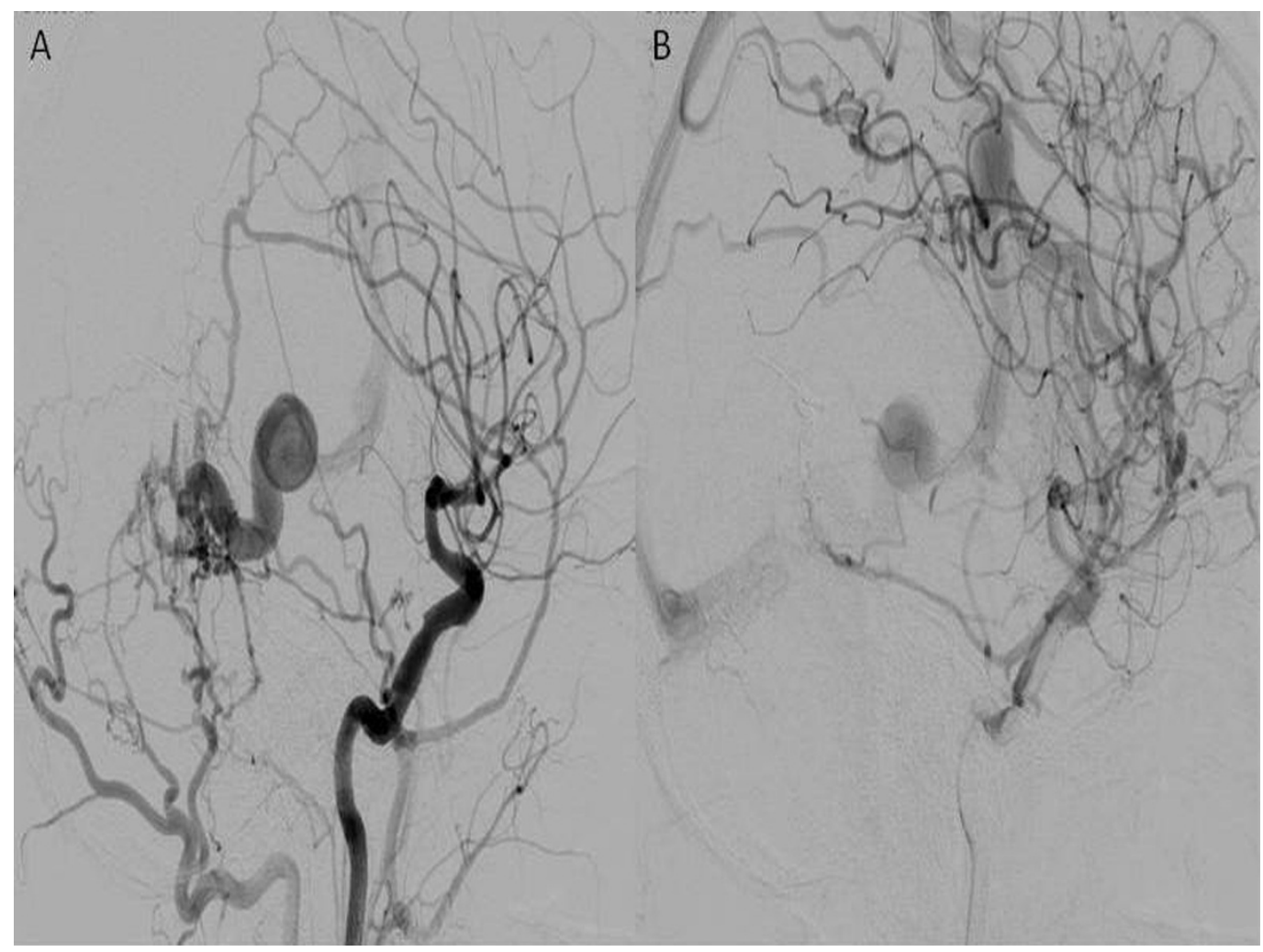

FIGURE 3: Fig. 3A\&B Admission cerebral angiogram demonstrating hypertrophied middle meningeal branch which connects to a nidus near the junction of the left vein of Labbe with the transverse sinus.

Additional arterial supplies are seen from the marginal tentorial artery and transcalvaria occipital branches. Notably, there is a relatively large $10 \mathrm{~mm}$ venous aneurysm located at Labbe's mid portion. The vein of Labbe filled briskly in retrograde fashion and drains anteriorly into the cavernous sinus and what appears to be the vein of Trolard, which then drains into the superior sagittal sinus.

Using Cognards' classification, both lesions were graded IIA/B [6].

Compounding the situation was angiographic evidence of left temporal delayed arterial transit time, presumably secondary to venous hypertension. There was associated shift of the left middle cerebral artery main trunk and branches. 


\section{Cureus}

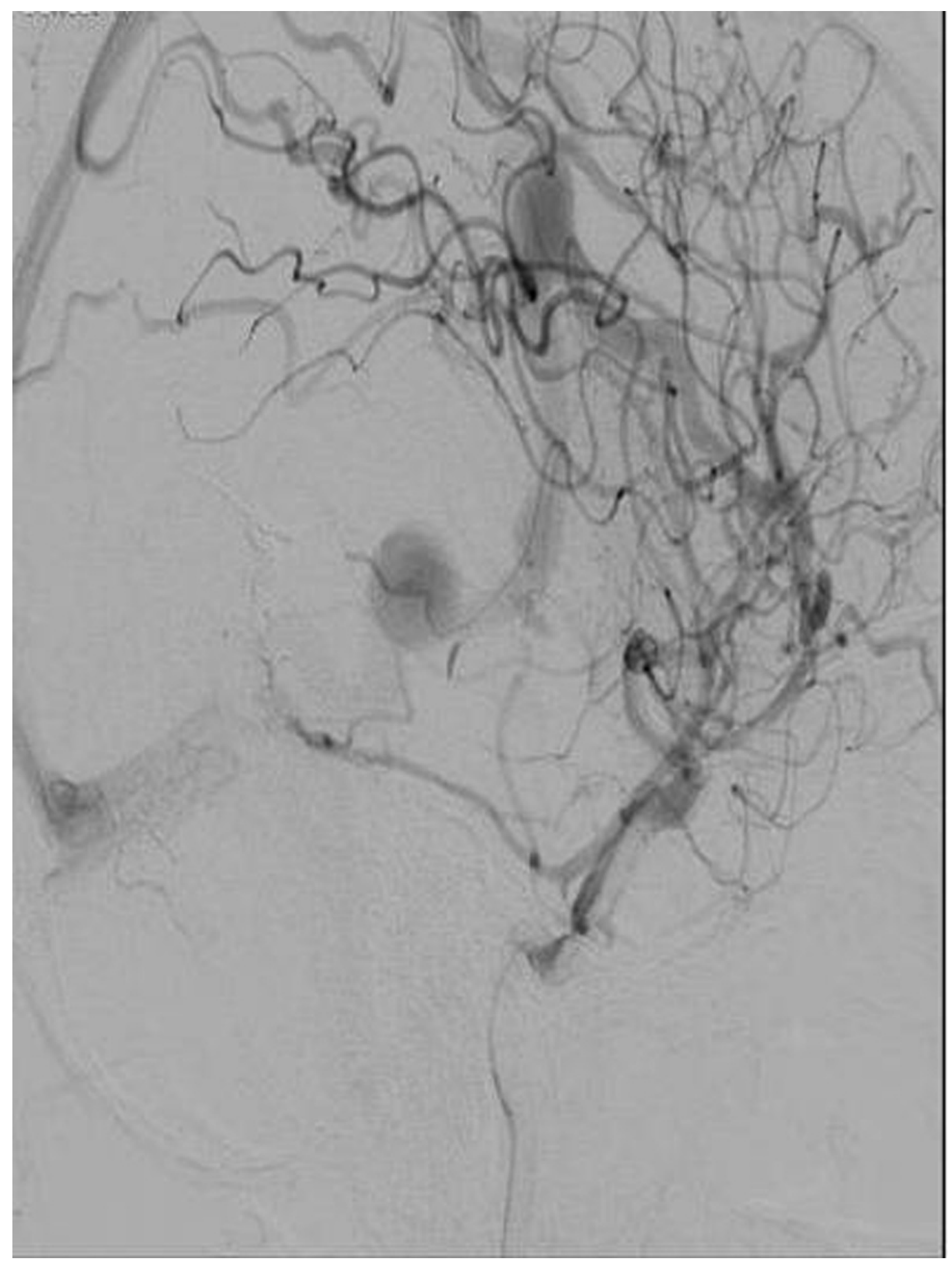

FIGURE 4: Fig. 4 Cerebral angiogram showing evidence of left temporal delayed arterial transit time, presumably secondary to venous hypertension

With associated shift of the left middle cerebral artery main trunk and branches.

\section{Endovascular management}

Arterial access of the malformation was gained via the middle meningeal artery. A Mirage [Micro Therapeutics, Inc., Irvine, CA/Hydrophylic Guidewire] wire was advanced into the more distal aspect of the arterial pedicle. A Marathon catheter [Marathon Flow Directed 


\section{Cureus}

Microcatheter; eV3 Neurovascular, Inc., Irvine, CA, USA] was then advanced and placed near the nidus of the dural AVM and close to the vein of Labbe. At this point, the Marathon catheter was prepped with $0.5 \mathrm{ml}$ of dimethyl sulfoxide (DMSO). This was followed by a $0.4 \mathrm{ml}$ infusion of Onyx-18 into the malformation nidus. This appeared to penetrate a portion of the vein of Labbe as well. However, as Onyx reached the vein, there was some retrograde reflux of embolization liquid material, and infusion was discontinued. Additional Onyx infusion was made using the plug-and-push technique, but no further forward flow of embolization material was achieved into the nidus. A second round of liquid embolization was performed into the dural network of branches without reaching the nidus. Final control angiography demonstrated partial embolization of the malformation, with some inflow-filling reduction within the nidus, although this did not increase overall intracranial transit time which remained slow due to persistent venous hypertension. The fistula was not completely obliterated due to the concern that the Onyx material might penetrate too far into the cortical vein and result in venous ischemia. This led to less aggressive treatment with the glue embolization material setting quickly. The patient suffered no complications associated with this procedure. Although a transvenous approach was contemplated, venous access was felt to be limited, and surgical disconnection was considered a more straightforward option.

\section{Microsurgical management}

The surgical approach began with a left-sided sub-temporal/temporal craniotomy during which an increased amount of transcalvarial arterial feeders were noted. On opening the dura, an arterialized venous structure was identified proximal and distal to the venous aneurysm. In order to decrease intracranial pressure, the hematoma was entered and evacuated through a corticotomy, achieving significant brain relaxation. At this point, a temporary clip was placed on the vein between the fistulous area and the venous aneurysm, allowing further evacuation of the hematoma. Significant bleeding occurred, likely as a result of intracranial decompression and was addressed by placing a second temporary clip on the vein distal to the aneurysm which stopped the bleeding. Intraoperative angiography showed timely filling and washout of the arterial circulation with the involved area draining through collateral veins. The temporary clips were then replaced with two permanent clips.

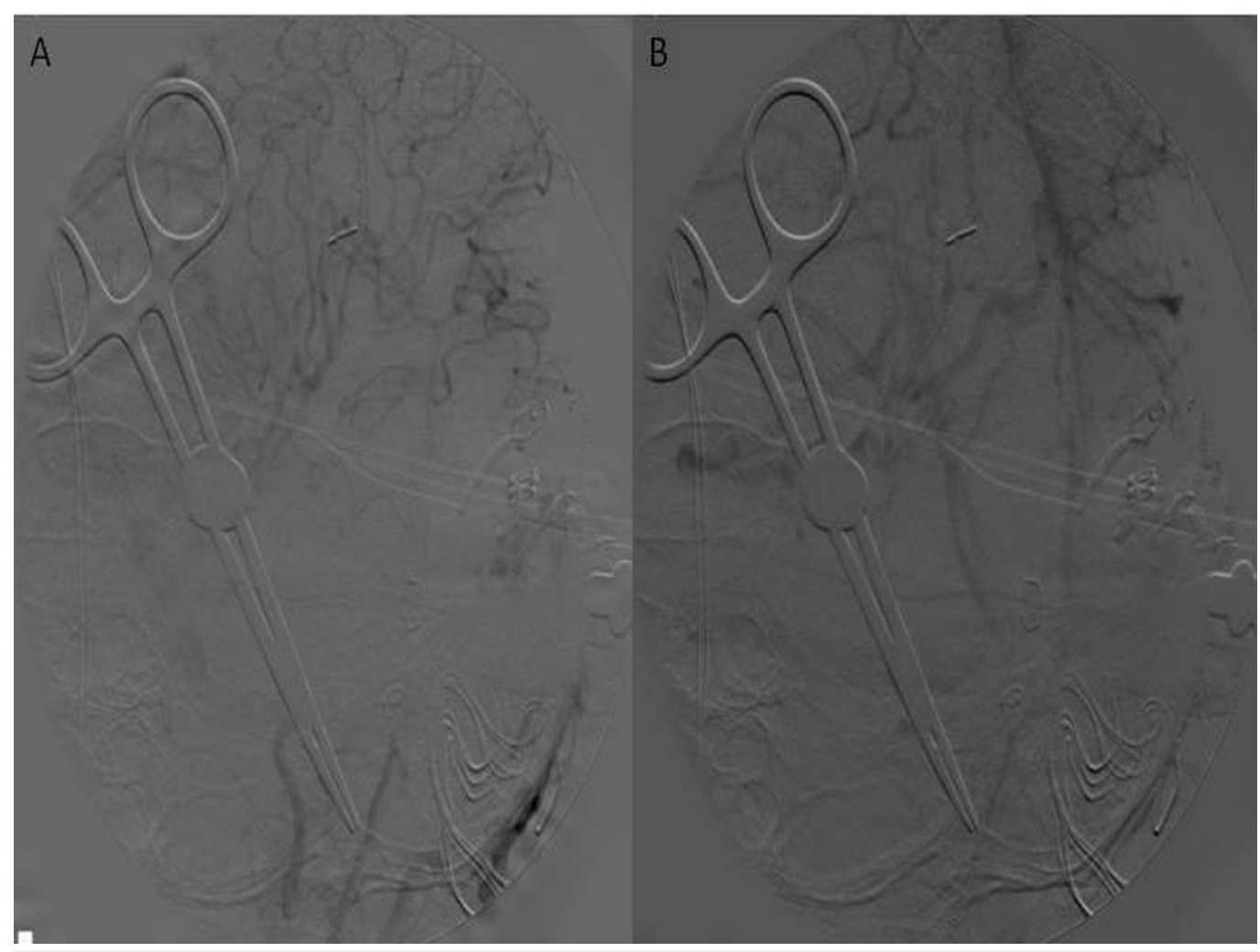




\section{Cureus}

FIGURE 5: Fig. 5A\&B. A) Intra-operative left common carotid artery angiography demonstrating complete occlusion of the dural fistula.

B) Venous phase showing no residual filling of the presumed ruptured venous aneurysm or presence of intracranial shunting.

A postoperative MRI demonstrated a complete occlusion of the fistulas, reduction in size of the feeding veins, and obliteration of the venous aneurysm.

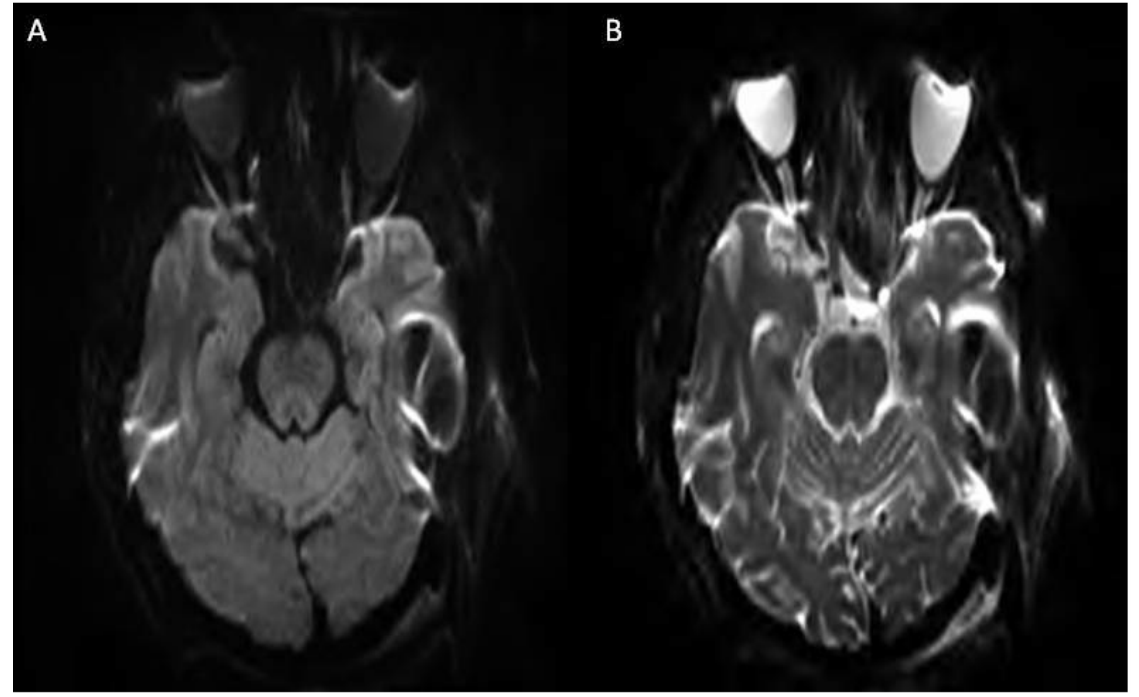

\section{FIGURE 6: Fig. 6A\&B. Post operative MRI showing typical post operative interval changes}

With evacuation of the left temporal lobe intraparenchymal hematoma and closure of the fistulas. The previously demonstrated sizable dilated draining veins of Labbe are reduced in size, and the venous aneurysm projecting into the hematoma is not identified.

Six weeks later, the contralateral lesion was treated through a similar microsurgical approach without preoperative embolization. The patient tolerated both procedures well and made a dramatic recovery without obvious neurological deficit.

\section{Discussion}

Multiple DAVMs are very uncommon lesions [1,3-5,7-9]. Areas of involvement may include the cavernous, transverse-sigmoid, sphenoparietal, sinuses, tentorium, craniocervical junction, and 
spinal locations $[4,5,10-15]$. The pathogenesis of multiple DAVMs is poorly understood. The occasional observation of DAVMs in infants supports a congenital origin [16]. In our case, the lack of obvious co-morbidities or predisposing conditions, and the bilateral, structurally identical nature of the lesions may point to a congenital origin. A number of theories could explain this phenomenon. First, a common genetic pathway may have triggered the over expression of genes related vascular transforming growth factor (VTGF), a multifunctional cytokine known to modulate tissue development and repair processes, including cell differentiation, cell cycle progression, cellular migration, adhesion, and extracellular matrix production. In the setting of VTGF over expression, the loss of function for TGF-Beta signaling proteins can result in vascular dysplasia. Finally, uncontrollable vascular dysplasia acts on endoglin and activin-like kinase-1 (ALK-1), which is a transmembrane kinase to promote angiogenesis and vascular growth [17].

Another possibility could be that vascular growth factors were activated by a previous anoxic or ischemic insult at some point, laying the foundation for delayed development of bilateral mirror image dural arteriovenous fistulas [18]. In either case, if the insult occurred at the time that the dural venous sinuses were forming, bilateral mirror image lesions may have developed. Some authors also suggest that angiogenetic and fibroblastic factors play an important role in the development of congenital malformations. A link between venous hypertension and venous sinus thrombosis has been associated with the development of acquired fistulae $[3,19]$.

The natural history of the disease is also variable. In general, aggressive neurological behavior has been linked to leptomeningeal venous drainage, variceal or aneurysmal venous dilatations, and galenic drainage [7]. Others propose that progression is associated with increased recruitment of arterial supply from additional vessels combined with hypertrophy of the existing ones $[3,20]$. Of interest in our report, the larger lesion had significant arterial recruitment from the middle meningeal artery, marginal tentorial and transcalvarial occipital branches, hypertrophied inflow-vessels to the malformation, and a venous aneurysm. In our patient, the possibility exists that those factors contributed to a more aggressive course.

DAVMs are classified using several classification systems primarily based on their venous drainage to predict the risk of brain hemorrhage $[6,21,22]$. According to the Borden-Shucart grading system, Type I dural arteriovenous fistulas exhibit antegrade drainage through a venous sinus; Type II exhibit antegrade venous sinus and retrograde cortical venous drainage; and Type III exhibit only retrograde cortical venous drainage [21]. The University of California, San Francisco system categorizes fistulas as Grade 1, no venous restriction with antegrade flow; Grade 2, ante- and retrograde venous drainage with or without cortical venous drainage; Grade 3, solely retrograde and cortical venous drainage; and Grade 4, cortical venous drainage only. However, Cognard's system provides more detailed information on the presence of normal or abnormal venous drainage, the presence or absence of cortical venous recruitment, and also takes into account the spinal perimedullary venous drainage [6,22]. Thus, it enables accurate comparison of clinical and radiological parameters.

\section{Conclusions}

We describe an unusual case of bilateral dural AVMs involving the transverse sigmoid junction. Both lesions were associated with retrograde cortical venous drainage, and the larger left-sided lesion presented with a large hemorrhage necessitating surgical intervention. The origin of these lesions remains poorly understood and this case may add to our understanding of this entity.

\section{Additional Information}

\section{Disclosures}


Human subjects: All authors have confirmed that this study did not involve human participants or tissue. Animal subjects: All authors have confirmed that this study did not involve animal subjects or tissue. Conflicts of interest: In compliance with the ICMJE uniform disclosure form, all authors declare the following: Payment/services info: All authors have declared that no financial support was received from any organization for the submitted work. Financial relationships: All authors have declared that they have no financial relationships at present or within the previous three years with any organizations that might have an interest in the submitted work. Other relationships: All authors have declared that there are no other relationships or activities that could appear to have influenced the submitted work.

\section{References}

1. Gist TL, Rangel-Castilla L, Krishna C, Roman GC, Cech DA, Diaz O: Endovascular management of six simultaneous intracranial dural arteriovenous fistulas in a single patient. Case report. J Neurointerv Surg. 2014, 6: e16. 10.1136/neurintsurg-2012-010619.rep

2. Houser OW, Campbell JK, Campbell RJ, Sundt TM Jr: Arteriovenous malformation affecting the transverse dural venous sinus-an acquired lesion. Mayo Clin Proc. 1979, 54:651-661.

3. Sencer A, Kiris T: Intracranial dural arteriovenous fistulas: A brief review on classification and general features. Review Article. Turkish Neurosurgery. 2006, 16:57-64.

4. Barnwell SL, Hallbach W, Dowd CF, Higashida RT, Hieshima GB, Wilson CB: Multiple dural arteriovenous fistulas of the cranium and spine. Am J Neuroradiol. 1991, 12:441-5.

5. van Dijk JM, TerBrugge KG, Willinsky RA, Wallace MC: Multiplicity of dural arteriovenous fistulas. J Neurosurg. 2002, 96:76-8.

6. Cognard C, Gobin YP, Pierot L, Bailly AL, Houdart E, Casasco A, Chiras J, Merland JJ: Cerebral dural arteriovenous fistulas: clinical and angiographic correlation with a revised classification of venous drainage. Radiology. 1995, 194:671-80.

7. Awad IA, Little JR, Akrawi WP, Ahi J: Intracranial dural arteriovenous malformations: Factors predisposing to an aggressive neurological course. J Neurosurg. 1990, 72:839-850.

8. Berenstein A, Lasjaunias P, TerBrugge KG: Surgical Neuroangiography, second edition, pp 565-607. Springer, Berlin Heildeberg; 2004.

9. Kuwayama N, Takaru A, Nishijima M, Endo S, Hirao M: Multiple dural arteriovenous malformations. J Neurosurg. 1989, 71:932-934.

10. Chaudhary MY, Sachdev VP, Cho SH, Weitzner I, Puljic S, Huang YP: Dural arteriovenous malformation of the major venous sinuses: an acquired lesion. Am J Neuroradiol. 1982, 3:1319.

11. Diez Lobato R, Escudero L, Lamas E: Bilateral dural arteriovenous fistula in the region of the cavernous sinus. Neuroradiology. 1978, 15:39-43.

12. Graeb DA, Dolman CL: Radiological and pathological aspect of dural arteriovenous fistulas . J Neurosurg. 1986, 64:962-967.

13. Sato K, Endo T, Niizuma K, Fujimura M, Inoue T, Shimizu H, Tominaga T: Concurrent dural and perimedullary arteriovenous fistulas at the craniocervical junction: case series with special reference to angioarchitecture. J Neurosurg. 2013, 118:451-459.

14. Shankar JJS, TerBrugger KG, Krings T: Multiple spinal and cranial dural arteriovenous fistulas. Case report. J Neurosurg Spine. 2011, 15:113-116.

15. Watanabe T, Matsumaru Y, Sonobe M, Asahi T, Onitsuka K, Sugita K, Takahashi S, Nose T: Multiple dural arteriovenous fistulae involving the cavernous and sphenoparietal sinuses . Neuroradiology. 2000, 42:771-774.

16. Ushikoshi SU, Kikuchi Y, Miyasaka K: Multiple dural arteriovenous shunts in a 5-year-old boy . Am J Neuroradiol. 1999, 20:728-730.

17. Young WL, Yang GY: Are there genetic influences on sporadic brain arteriovenous malformations?. Stroke. 2004, 35:2740-2745.

18. Nussbaum ES, Heros RC, Madison MT, Awasthi D, Truwit CL: The pathogenesis of arteriovenous malformations: Insights provided by a case of multiple arteriovenous malformations developing in relation to a developmental venous anomaly. Neurosurg. 1998, 43:347-352.

19. Awad IA, Barrow DL: Dural arteriovenous malformations, first edition. American Association of Neurological Surgeons Publications, Illinois, USA; 1993. 


\section{Cureus}

20. Steiger HJ, Hanggi D, Schmid-Elsaesser R: Cranial and spinal dural arteriovenous malformations and fistulas: An update. Acta Neurochir Suppl. 2005, 94:115-22.

21. Borden JA, Wu JK, Shucart WA: A proposed classification for spinal and cranial dural arteriovenous fistulous malformations and implications for treatment. J Neurosurg. 1995, 82:166-79.

22. Cognard C, Casaco A, Toevi M, Houdart Chiras J, Merland JJ: Dural arteriovenous fistulas as a cause of intracranial hypertension due to impairment of cranial venous outflow. J Neurol Neurosurg Psychiat. 1998, 65:308-16. 